EESTI NSV TEADUSTE AKADEEMIA TOIMETISED. VIII KÖIDE

BIOLOOGILINE SEERIA. 1959, NR. 3

ИЗВЕСТИЯ АКАДЕМИИ НАУК ЭСТОНСКОЙ ССР. ТОМ VIII

СЕРИЯ БИОЛОГИЧЕСКАЯ. 1959, № 3

\title{
НОВЫЙ ВИД РОДА ANACERTAGALLIA ZACHW. (HOMOPTERA: IASSIDAE) ИЗ ЭСТОНИИ
}

\author{
Ю. Г. ВИЛЬБАСТЕ, \\ кандидат биологических наук
}

\begin{abstract}
При анализе материалов, собранных в альварных лесах Эстонии, было обнаружено несколько экземпляров одного вида Anacertagallia из группы venosa (Fall.), которые отличаются от известных до сих пор видов этой группы небольшими размерами и строением гениталий самца. При просмотре остальных материалов, относящихся к этой же группе рода Anacertagallia и имеющихся в коллекциях Института зоологии и ботаники $\mathrm{AH}$ ЭССР, обнаружено значительное число экземпляров этого вида, собранных в основном в прибрежной зоне Эстонской ССР. Кроме того, один самец находился также в коллекции Г. Флора.
\end{abstract}

Ниже приводится описание этого нового вида.

\section{Anacertagallia estonica n. sp.}

С а м е ц по внешнему виду очень похож на $A$. venosa (Fall.), только основная окраска у него более светлая - беловато-желтая (у A. venosa охряно-желтая), а рисунок более темный. На темени средняя линия, 2 больших закругленных пятна и треугольные пятна, расположенные латерально от последних (заходящие назад до $2 / 5$ ширины темени и продолжающиеся на лицевой поверхности головы), почти целиком черные. Лоб өграничен сверху черной дугой, ниже которой расположено узкое светлое гятно, часто разделенное на две части. Остальная часть лба большей частью черная, с нерегулярными светлыми пятнами; самый нижний край щек светлый. Переднегрудь с черной продольной средней линией, двумя латеральными широкими поперечными пятнами (на заднем крае которых небольшое светлое поперечное пятно) на передней части и с нерегулярным затемнением на задней части; последнее может быть иногда почти сплошь черным. Щиток с черными боковыми треугольниками и с черной или черно-бурой фигурой в середине.

Надкрылья кожистые, слабо прозрачные, с темными, черновато-бурыми или почти черными жилками. Последние могут быть местами, особенно в основании крыла, прерваны светлыми, иногда совсем желтовато-белыми (или цвета слоновой кости) участками. Зачастую почти вся корневая часть надкрылий желтовато-белая, непрозрачная.

Ноги с черно-бурыми пятнами и линиями.

Брюшко большей частью черное, с узкими светлыми задними краями сегментов. Генитальные сегменты, а также задняя часть субгенитальной пластинки и передние части генитальных пластинок светлее общей окраски брюшка. 
С а мка. Рисунок почти такой же, как у $\hat{o}$, только светлее и черный пигмент отчасти редуцирован. В черный цвет окрашены лишь круглые пятна на темени, пятна на передней части переднеспинки, обычно сильно редуцированные, боковые треугольники щитка и рисунок на лбу. Последний обычно состоит из черной (или иногда даже бурой) продольной средней линии и группы черных точек, расположенных по обеим сторонам последней. Весь остальной рисунок, в том числе и жилки надкрылий, светло-бурый. Продольные линии темени и переднеспинки -обычно разделены светлой продольной линией на две части. Брюшко сверху черное, со оветлыми задними краями тергитов и широкими светлыми боковыми краями и задним краем, снизу большей частью беловато-охряно-желтое, только средние части первых стернитов затемнены. На каждом сегменте брюшного ободка имеется небольшое неправильное темное пятно. Генитальный сегмент светлый, только на заднем крае седьмого стернита узкое поперечное темное пятно и неправильное пятно на переднем крае боков пигофера. Яйцеклад темный.

Ге н и т а л и и $\hat{o}$. Субгенитальная пластинка довольно широкая, умеренно суживающаяся назад. Генитальные пластинки относительно (по сравнению с другими видами) короткие (рис. $1, A)$. Грифельки длинные, на концах острые, с наружнной стороны на них находится поле с мельчайшими зубчиками (рис. 1,5$)$. Эдеагус дугообразный, в профиль почти ровной ширины, в основании с большой лопастью, до самого нижнего края покрыт зубчиками (рис. 1 и $4, B$ и $\Gamma$ ). Боковые лопасти обычной формы (рис. $1, Д)$. Анальная трубка с отростками такого же типа, как у A. venosa (Fall.) (рис. 1,E).

Г е н и т а л и и ․ . Седьмой стернит брюшка немного длиннее предыдущего; задний край его слегка волнистый, в середине - со слабым вырезом (рис. 1 , ЖK).

Изм ерения в милли ме т рах $x^{*}$. $\delta(7)$ : общая длина до конца надкрылий $2,55-2,97(2,81)$, до конца брюшка $-2,57-3,02(2,72)$; длина темени $-0,15-0,22(0,19)$; гцирина головы с глазами - 1,05-1,14 $(1,09)$; ширина темени между глаз - 0,67 $-0,70(0,68)$; длина переднеспинки - $0,43-0,50(0,46)$; ширина переднеспинки $0,96-1,04(0,98)$; длина надкрылий $-2,11-2,35(2,28)$; нанбольшая ширина надкрылий $-0,85-0,93(0,89)$; длина задней голени - $1,40-1,55(1,49)$.

ㅇ (15): общая длина до конца надкрылий - $3,01-3,56(3,14)$, до конца брюшка $-3,25-4,13$ ( 3,73$)$; длина темени - $0,20-0,29(0,23)$; ширина головы с глазами - 1,17-1,31 (1,23); шнрина темени между глаз - $0,73-0,87(0,79)$; длина переднеспинки - $0,49-0,59(0,53)$; ширина переднеспинки - $1,03-1,17(1,10)$; длина надкрылий $-2,39-2,77(2,57)$; нанбольшая ширина надкрылий $-1,00-1,07(1,02)$; длина задней голени $-1,53-1,78(1,70)$.

Как уже упоминалось, этот вид очень сходен с A. venosa (Fall.) и другими видами этой группы, отличаясь от них более мелкими размерами и более темным рисунком самца. Наиболее существенные отличительные признаки имеются в строении гениталий самцов. Так, по форме эдеагуса описываемый вид немного похож на $A$. ribauti (Oss.), но базальное pacширение у него крупнее и покрыто по всей длине зубчиками, как у A. venosa (Fall.). Отростки анальной трубки такого же типа, как у A. venosa (Fall.). Кроме того, на наружном крае грифельков имеются мелкие зубчики, отсутствующие у экземпляров A. venosa (Fall.), имевшихся у автора для сравнения. У $A$. ribauti (Oss.) этих зубчиков еще больше и кроме них имеется еще один более крупный отросток.

Голотип $\delta$, аллотип ㅇ, 7 ㅎ 17 ㅇ паратипы - Эстонская ССР, Раплаский район, лесничество Куузику, обход Абру, альвар с редкими деревьями, 7 VIII 1956 (Вильбасте).

\footnotetext{
* Bсе измерения произведены на заспиртованных материалах,
} 


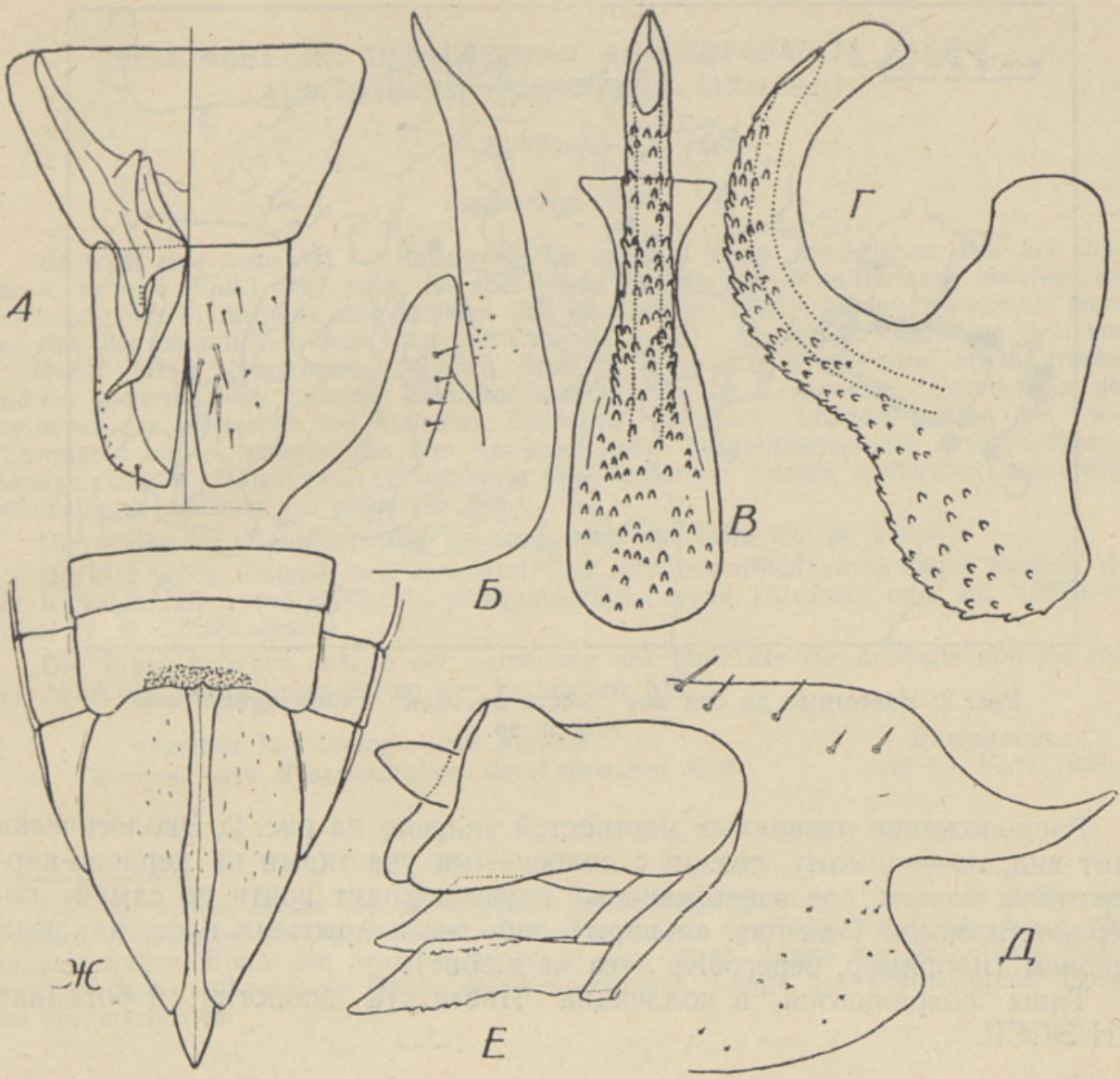

Pнс. 1. Anacertagallia estonica n. sp. A - Субгенитальная пластинка и генитальные пластинки (слева - внд сверху, справа - вид снизу) (увел. 60x); $Б$ - грифелек (увел. 200x); $B$ - эдеагус, вид сзади (увел. 210x); $\Gamma$ - эдеагус, внд сбоку (увел. 210x); Д-боковая лопасть (увел. $96 \mathrm{x}) ; E$ - анальная трубка с отростками (увел. 290x); $\mathcal{K}$ - задний конец брюшка самки снизу (увел. 28x).

Паратипы: Р а пл а ски й р ай он, лесничество Куузику, обход Липсту, альвар с редкими деревьями, 5 VIII 1957, 2 \&, 3 으 (Вильбасте). О с т ров С a р е м а : морское побережье к западу от Питканина, 6 VII 1939, 1 ; ; морское побережье вблизи c. Антсла, 6 VII 1939, I §, 1 ㅇ; морское побережье вблизи с. Ансекюла, 10 VII 1939 , 2 ๙ ; морское побережье вблизи с. Сандра, 13 VII 1939, 1 s; морское побережье вбли-

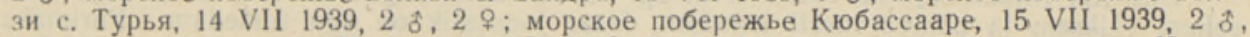
1 ; глинт Пулли у с. Хаanca, 19 VII 1939, 21 o , 6 o; морское побережье у с. Хинду, 19 VII 1939, 11 3 , 8 \%; северный конец мыса Трийги, 19 VII 1939, 1 क; морское побережье у с. Соэла, 20 VII 1939, 11 ㅅ, 17 ; морское побережье вблизи с. Лийкюла,

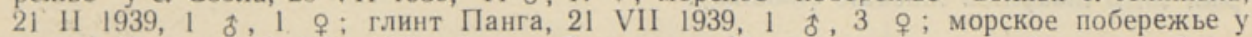
глинта Ниназе, 22 VII 1939, 2 ㅇ. Остр о в $\dot{\text { y }}$ х у: морское побережье вблизи c. Линнузе, 16 VII 1939, 4 of, 5 o ; морское побережье у гавани Куйвасту, 17 VII 1939 ; морское побережье у глинта Каутлику, 17 VII 1939, 2 \%; мыс Сеанина вблизи с. Ныммкюла, 17 VII 1939, 24 ई , 12 ㅇ, 6 нимф; морское побережье у с. Когува, 18 VII 1939, 3 б. Ост ро в В и льс анд и: морсксе побережье у маяка Вильсанди, 24 VII 1939 , 2 s, 2 우 ; морское побережье бухты Вахемере, 24 VII 1939, 2 o , 6 \% ; Вильсанди, 16 (4) VII 1952 (Г. Флор). О с т р в А б р у к а: западное побережье мыса Пиканина, 26 VII 1939, 7 , 14 ᄋ. П а й д е с и й р ай он: лесничество Варангу, обход Мути, сухой луг, i VII 1939, 11 ๙ै, 17 우. 


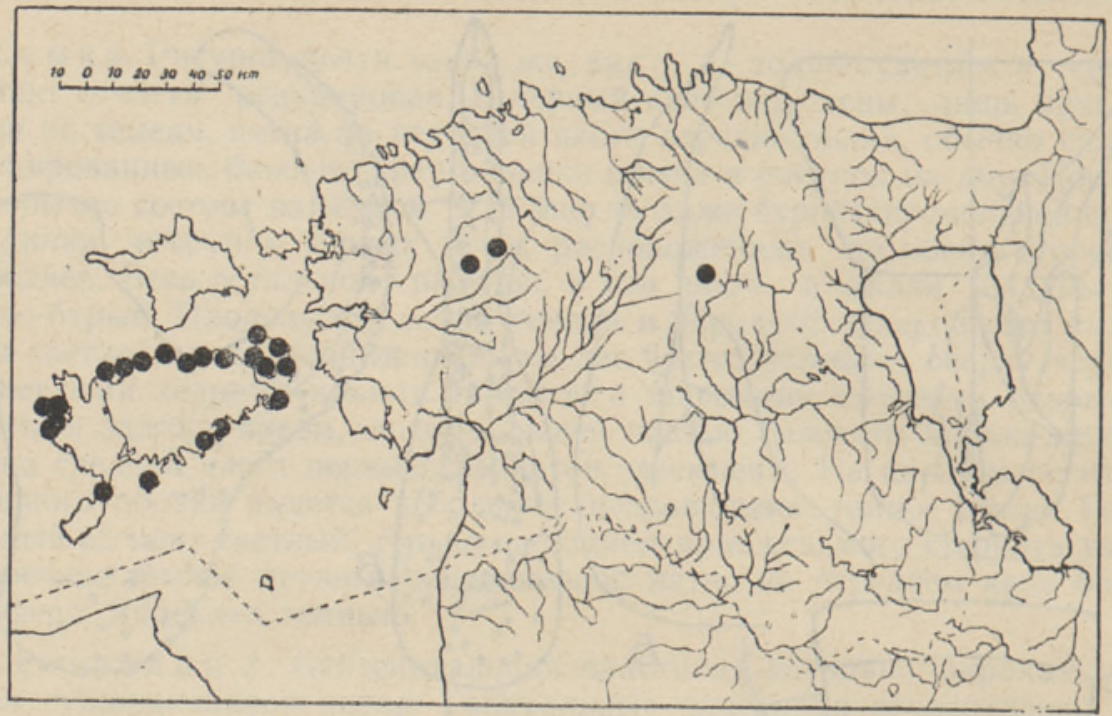

Рис. 2. Известные до сих пор места находок Anacertagallia estonica $\mathrm{n} . \mathrm{sp}$.

Расположение названных местностей указано на рис. 2. Экологически этот вид, по-видимому, связан с солнечными участками на дерново-карбонатных почвах, где известняковый грунт доходит почти до самой поверхности земли (так наз. альвары) либо же покрытыми известняковым щебнем (например, береговые луга на щебне).

Типы сохраняются в коллекции Института зоологии и ботаники AH $Э$ CCP.

Институт зоологии и ботаники Академии наук Эстонской ССР

Поступила в редакцию 19 III 1959

\title{
HOMOPTERA: IASSIDAE - PEREKONNA ANACERTAGALLIA ZACHW. UUS LIIK EESTIST
}

\author{
J. Vilbaste, \\ bioloogiateaduste kandidaat
}

Resümee

Uus liik Anacertagallia estonica n. sp. on lähedane liigile $A$. venosa (Fall.), kuid sellest väiksem ja põhivärvuselt heledam; isase joonestik on aga tumedam. Parimaks eristamistunnuseks on isase genitaalide ehitus (vt. joon. 1, $A, E$ ). Liik esineb meil laialdaselt (joorı. 2) lubjakiviklibul asuvatel rannaniitudel vōi neil aladel, kus lubjakivialuspõhi tuleb maapinna lähedale (looalad).

Eesti NSV Teaduste Akadeemia

Zooloogia ja Botaanika Instituut
Saabus toimetusse

19. III 1959 


\section{EINE NEUE ART DER GATTUNG ANACERTAGALLIA ZACHW. AUS ESTLAND (HOMOPTERA: IASSIDAE)}

\section{J. Vilbaste}

\section{Zusammenfassung}

Es wird eine neue Art - Anacertagallia estonica n. sp. beschrieben. Die Art steht $\operatorname{der} A$. venosa (Fall.) sehr nahe, ist aber etwas kleiner, die Grundfärbung bleicher, die Zeichnung des Männchens aber dunkler. Die deutlichsten Unterscheidungsmerkmale weist der Bau der männlichen Genitalien auf (Abb. 1, $A-E$ ). So ist der Aedeagus dem von A. ribauti (Oss.) einigermassen ähnlich, doch ist die basale Erweiterung etwas grösser und der ganzen Länge nach mit Zähnchen bedeckt (wie bei $A$. venosa). Ausserdem ist der Stylus an der Innenseite mit kleinsten Zähnchen versehen. Letztere fehlten bei den Exemplaren von $A$. venosa, die dem Verfasser als Vergleichsmaterial zur Verfügung standen. Bei A. ribauti sind Zähnchen in noch grösserer Anzahl vorhanden, ausserdem befindet sich daneben ein grösserer Zahn.

Die Masse für Männchen und Weibchen sind auf Seite $200 \mathrm{zu}$ finden. ${ }^{1}$

Die Art ist in Estland weit verbreitet (Fig. 2), namentlich an sonnigen Stellen, wo der Kalksteinuntergrund bis an die Bodenoberfläche reicht (Alvaren) oder auf Kalksteingeröll (z. B. Strandwiesen).

Die Typen befinden sich in der Sammlung des Institutes für Zoologie und Botanik der Akademie der Wissenschaften der Estnischen SSR.

Institut für Zoologie und Botanik

der Akademie der Wissenschaften der Estnischen SSR
Eingegangen am 19. März 1959

1 Die einzelnen Masse sind in folgender Reihenfolge gegeben: Länge zur Spitze der Vorderflügel, Länge zur Spitze des Hinterleibes, Länge des Scheitels, Breite des Kopfes mit den Augen, Breite des Scheitels zwischen den Augen, Länge des Pronotums, Breite des Pronotums, allergrösste Breite des Vorderflügels, Länge des Vorderflügels, Lănge der Hinterschienen. 